\title{
GUEST EDITOR'S NOTE
}

Throughout the first half of the twentieth century, cancer was viewed as an uncommon disease and a minor problem in Brazil. Health policy decision-makers believed control should be limited to hospital-based curative medicine and to isolated sanitary education initiatives that showed the value of early detection and treatment. The closing quarter of this past century saw far-reaching changes in Brazil's health system and within this context cancer began to be viewed as a public-health problem that could not be limited to curative medicine. Today the disease is at the center of the country's public health debates, and the focus of control efforts has shifted into primary care, where it encompasses preventive testing and the promotion of healthy habits. Yet despite these changes, problems persist. According to Brazil's National Cancer Institute (Instituto Nacional do Câncer, or INCA), the disease is the second leading cause of death in the country and it is estimated that nearly 500,000 new cases will occur in 2010. Although public anti-smoking policies have met with some success in bringing down the mortality rate for lung cancer, death rates for some other avoidable forms of the disease, like cervical cancer, are still high in Brazil.

The current consensus is that cancer deaths are not only the result of biological factors but also relate to living conditions, the efficacy of healthcare systems, and each society's specific cultural habits and norms. At the same time, it is ever more common for numerous cancer treatments to demand costly, cutting-edge technologies, which presents a particular health policy challenge in developing nations like Brazil, where poverty and the lack of basic health care coexist alongside state-of-the-art technology and a robust network of research and innovation in a variety of health fields.

In such a context, historical studies of the sciences and of health provide valuable tools in understanding the history of cancer and even contemporary aspects of the disease, which in turn implies that this research contributes to the success of efforts to control the disease.

The first studies to adopt this kind of historical approach date to the 1980s. When the branch of historiography known as the history of disease was enjoying its initial rapid growth, French physician and historian MarieJoseph Imbault-Huart published an article on the history of cancer in a 1985 issue of L'Histoire dedicated entirely to the history of disease. The year after, she published another article in a book likewise focused on this branch of historiography, organized by historian Jacques Le Goff. Further historical studies on cancer appeared the next decade, foremost among them the now classic Naissance d'un fléau: histoire de la lutte contre le cancer (1890-1940) (The fight against cancer: France 1890-1940), where Patrice Pinell provides a detailed picture of France's struggle against the disease during those years. Following in the steps of these pioneering studies, a number of other researchers turned to the topic, earning it a definitive place on the research agenda in the history of disease. 
In 2007, the Bulletin of the History of Medicine devoted a special issue to cancer in the twentieth century. Scholars from various countries around the world addressed education and health, treatments, prevention, and risks, among other issues.

Because there is a close relationship between cancer and advanced areas of science and technological innovations, researchers from sociology and the history of the sciences soon displayed growing interest in the theme, especially those in the field we have come to call the social study of the sciences. Of special note here are investigations into risk, in all its shades of meaning. A gamut of other considerations, like patient viewpoint, prevention campaigns, anti-smoking policies and advertising, and the relation between cancer treatment and military medicine, have been the target of thoroughgoing studies by authors such as Ilana Löwy, Robert Aronowitz, Elizabeth Kirsten, Robert Proctor, Ornella Moscucci, and David Cantor.

Although much on the topic of cancer has been produced in Brazil's field of medicine and collective health, there have been few historical studies to date. The first title of a historical nature was released 21 years ago: História e saúde pública: a política de controle do câncer no Brasil (History and public health: cancer control policy in Brazil). Edited by Regina Bodstein, this book painted a vast panorama of government initiatives to fight the disease from the early twentieth century through the 1980s. A more comprehensive publication on the disease came out recently: De doença desconhecida a problema de saúde pública: o Inca e o controle do câncer no Brasil (From an unknown disease to a public health problem: INCA and cancer control in Brazil). Written by myself and the researcher Cristina Fonseca, the book retraces the path taken in the earlier volume, this time relying on new sources that let us expand the analysis of twentieth-century medical action against the disease.

Other studies continue to appear, especially on cancer institutes and policies.

This issue of História, Ciências, Saúde - Manguinhos is the first collection of studies on this topic to be published in Brazil. In its pages you will find different approaches to the disease by researchers from here and from other countries. We hope that this publication will make an important contribution to analyses of cancer in the history of the sciences and of health.

Luiz Antonio Teixeira 